\title{
Simultaneous Distraction and Extension Techniques for the Management of Loose Body in Elbow of Professional Cricket Player: A Case Report
}

\section{Keramat Ullah Keramat ${ }^{1}$, Ubaid Ullah Bilal ${ }^{2}$}

${ }^{1}$ Associate professor, Helping Hand Institute of rehabilitation Science, Mansehra, Khyber Pakhtunkhwa, Pakistan

${ }^{2}$ Physiotherapist, Helping Hand Institute of rehabilitation Science, Mansehra, Khyber Pakhtunkhwa, Pakistan

Article Info.

Received: Feb 3, 2020

Acceptance: Oct 13, 2021

Conflict of Interest: None

Funding Sources: None

Address of Correspondence

Dr Keramat Ullah Keramat

Email Id: karamatjee@yahoo.com

ORIC Id: 0000-0002-1847-1850

Cite this article as: Keramat KU, Bilal

UU. Simultaneous Distraction and

Extension Techniques for the

Management of Loose Body in Elbow

of Professional Cricket Player: A

Case Report. JRCRS. 2021; 9(2):84-

86.

DOI: $\underline{10.53389 / J R C R S .2021090210}$

\section{S u m m a r y}

A patient who was a fast-professional bowler presented with pain during the end range of extension of right elbow, intermittently during fast bowling. The subject was otherwise healthy, and his physical examination was insignificant. Pain at the end of elbow extension after the throwing was the main subjective finding. Isometric resisted test for extension was not eliciting pain and the ROM of the elbow appeared within normal limits. Over pressure at the end range was reproducing the symptoms. A loose body was suspected and treated with simultaneous traction and extension maneuver. The patient reported no pain after several weeks of treatment. The novel techniques might be helpful in the management of loose bodies of elbow joint.

Keyword: Loose body, Traction, Distraction
Case Presentation

A 24-year-old young professional cricket player was seen at the outpatient department of helping hand institute of rehabilitation Sciences Mansehra. He was a fast bowler who participated at several international cricket tournaments. He complained of off and on sever pain in his right elbow after fast delivery of the cricket ball for the last 7 months. He was not using any medicine and his past medical history was unremarkable. The pain started suddenly during bowling in a practice session and successive deliveries would further aggravates his pain. He had no history of direct injury or a fall. A rest from bowling for several weeks did not improve his pain during bowling. He had mild resting pain on the day he was seen and over extension. He had taken several physiotherapy treatment sessions but there was no relief in his pain. Pain would improve at rest and with analgesics.

On examination there was no abnormality detected at cervical spine and shoulder joint except gleno-humeral internal rotation deficits and there was no visible sign of effusion or inflammation at the posterior aspect of the elbow joint. Mild tenderness around olecranon process was found. Passive over extension was painful and isometric resisted extension at slightly flexed elbow was $5 / 5$. There was no pain in isometric resisted test for biceps, brachialis and brachioradialis with power of 5/5. Valgus and Varus stress were asymptomatic.

Based on the review on his history and clinical findings, the therapist suggested that there may be presence of loose bodies in the posterior segment of the elbow.

Investigations: An X-rays was done which showed no abnormality. A CT scan or MRI or arthroscopy was not advised.

- Differential Diagnosis

- Presence of loose bodies

- Triceps muscle strain

- Stress fracture olecranon process

- Olecranon spur

- Olecranon bursitis

- Tendon ossification

- Tennis elbow 
- Pitcher elbow (soft tissue impingement)

- Pulled elbow

- Cervical radiculopathies

- Treatment

As a loose body was suspected and a logical and rational procedure was adopted to move it away from inbetween the articular surfaces of olecranon and trochlea. The patient was asked to extend the elbow actively up to the point of pain. At this point a traction to the articular surfaces was applied and simultaneously the elbow was extended, in order to distract olecranon and trochlea and allow the loose body to move away from within the articular surfaces. The procedure was repeated 3 times. On re-assessment, the patient became asymptomatic and was advised to self-administer the maneuver if the symptoms recur.

Outcome and Follow Up: After 3 months patient visited the physical therapy department for another problem. He was examined for his elbow and no abnormality was found. He reported complete resolution of his elbow pain after the initial single treatment session

\section{Discussion}

A professional cricket player of one of the elite cricket club in Pakistan was successfully treated for loose body in his elbow. The condition is usually missed in clinical diagnosis. The adopted maneuver for the management of a loose body in the elbow is not reported in literature and is novel. The maneuver allows the loose body to move out from in between the articular surfaces. Arthroscopic and surgical intervention are in use but conservative managements are nonexistent to author's knowledge. ${ }^{1}$

Chronic musculoskeletal injuries are more common in cricket players. Acute problems due to trauma or injuries are also common. The incidence of acute problems is more in elbow and upper back regions. ${ }^{2}$

The prevalence of injuries in cricket players has increased due to game format changes, increasing number of matches played, and decreased rest between matches. Bowling accounts for $(41.3 \%)$ of total injuries in cricket players. Acute injuries are most common (64\%-76\%), followed by acute-onchronic (16\%-22.8\%) and chronic ones (8\%-22\%). ${ }^{3}$

There are many pathologies of elbow joint which are related to repetitive movement especially throwing. Among these are osteochondritis dissecans, fracture at the epiphysis of the proximal humerus, medial epicondylar apophasis, of the capitellum, ulnar collateral ligament tear. ${ }^{4}$ The degree of force at the elbow joint during throwing produces extreme valgus and extension overload. Biomechanical analysis of force, velocity, frequency and understanding of the movements while throwing can improve the risk for elbow related injuries while throwing. Tendinosis of the flexor-pronator muscle, neuritis of the ulna, impingement of the posterior structures and tendinopathy are the common pathologies seen in players like tennis, baseball, basketball, volley ball which involve excessive throwing. ${ }^{5}$

Fast bowlers in cricket generate a speed up to 150 $\mathrm{km}$ per hour. The amount of force generated in the kinetic chain of throwing a cricket ball is transmitted to the wrist through the elbow joint. This generated force is colossal and renders elbow at huge risk of injuries. Therefore, the possibility of a loose fragment of articular cartlige is possible due to the repeated extreme articular stress resembling direct injuries.

Younger athletes subjected to repetitive valgus stresses while in hyperextension (i.e., javelin throwers) present with valgus extension overload syndrome. This overload causes impingement of the olecranon tip in the olecranon fossa, Patient will have posterior elbow pain during physical examination when forced into full elbow extension. ${ }^{6}$

Posteromedial olecranon hypertrophy, chondral damage to the trochlea, osteophyte formation, , and loose bodies are the result of high valgus and extension forces at the elbow joint during throwing motion. ${ }^{7}$

Repetitive forceful extension and pronation of the elbow in throwers result in compressive forces that are transmitted from the radius to the capitellum. It may cause lesions which involve chondral or osteochondral fragments to be detached and result in an intra-articular loose body. ${ }^{8}$

The non operative treatment used for posterior elbow pathologies prior to surgical procedure is strengthening of biceps, brachioradialis, and brachialis muscles to control the rapid elbow extension that occurs during the deceleration phase of throwing. ${ }^{9}$

Supra physiologic stresses are placed across the elbow joint in throwing athlete from repetitive throwing motion. Over time, and occasionally acutely, this stress may damage the flexor-pronator mass, ulnar collateral ligament (UCL), ulnar nerve and cause bone exostosis. ${ }^{10}$

Can cause disabling pain and limited motion during repeated elbow extension can results in posterior elbow impingement which causes pain and limitation of motion Arthroscopic treatment are used for the effective management of pain, loss of range of motion, and returning athletes to previous levels of activity. 1

The treatment maneuver used for the management of this condition is simple, noninvasive and cost effective and 
therefore can be used as a first line of treatment in patients presented with similar problems. If not so effective only then can be the patient subjected to other treatments.

\section{References}

1. Koh JL, Zwahlen BA, Altchek DW, Zimmerman TA. Arthroscopic treatment successfully treats posterior elbow impingement in an athletic population. Knee Surgery, Sports Traumatology, Arthroscopy. 2018;26(1):306-11.

2. Mondam S, Shaik R, Prakash JJ, Fook JL, Nekkanti S. Surveillance of Musculoskeletal Symptoms and Anthropometric Variables among Four International Cricket Teams Competed in ACC Premier League Malaysia 2014. Asian Journal of Pharmaceutical Research and Health Care. 2016;8(2).

3. Pardiwala DN, Rao NN, Varshney AV. Injuries in cricket. Sports health. 2018;10(3):217-22.

4. Popchak A, Burnett T, Weber N, Boninger M. Factors related to injury in youth and adolescent baseball pitching, with an eye toward prevention. American journal of physical medicine \& rehabilitation. 2015;94(5):395-409.

5. Eygendaal D, Rahussen FTG, Diercks R. Biomechanics of the elbow joint in tennis players and relation to pathology. British journal of sports medicine. 2007;41(11):820-3.

6. Kane S, Lynch JH, Taylor JC. Evaluation of elbow pain in adults. American family physician. 2014;89(8):649-57.

7. CAIN JR EL, ANDREWS JR. Arthroscopic management of posterior elbow impingement in throwers. Techniques in Shoulder \& Elbow Surgery. 2001;2(2):118-30.

8. Puddu G, Giombini A, Selvanetti A. Rehabilitation of sports injuries: current concepts: Springer Science \& Business Media; 2013.

9. Azar FM, Wilk KE. Nonoperative treatment of the elbowin throwers. Operative Techniques in Sports Medicine. 1996;4(2):91-9.

10. Sethi $P$, Macken CJ. Evaluation and nonoperative treatment of the unstable throwing elbow. The Unstable Elbow: Springer; 2017. 141-57.

\section{Copyright Policy}

All Articles are made available under a Creative Commons "Attribution-NonCommercial 4.0 International" license. (https://creativecommons.org/licenses/by-nc/4.0/). Copyrights on any open access article published by Journal Riphah college of Rehabilitation Science (JRCRS) are retained by the author(s). Authors retain the rights of free downloading/unlimited e-print of full text and sharing/disseminating the article without any restriction, by any means; provided the article is correctly cited. JRCRS does not allow commercial use of the articles published. All articles published represent the view of the authors and do not reflect the official policy of IRCRC 